\title{
COARCTATION OF THE AORTA, DOUBLE MITRAL A-V ORIFICE, AND LEAKING CEREBRAL ANEURYSM
}

BY

\author{
J. N. P. DAVIES AND J. A. FISHER
}

From the University of Bristol

Received August 18, 1943

The purpose of this paper is to record and discuss the case of a boy with well-marked coarctation of the aorta, who made a complete recovery from subarachnoid hæmorrhage due to a leak from an intracranial aneurysm, only to die from rupture of a dissecting aortic aneurysm. A double mitral auriculo-ventricular orifice found at autopsy in this case is an extremely rare cardiac anomaly, only ten previous cases having been recorded (Abbott, 1927). In the present case the occasional diastolic or presystolic mitral murmur may have been the clinical counterpart of this anomaly. We can find only two previous cases in which recovery from a subarachnoid hæmorrhage in association with coarctation has been recorded-one in a girl, aged 12, reported by Lichtenberg and Gallagher (1933), and the other in a woman of 25, reported by Baker and Sheldon (1936) —and in neither case was the cerebrospinal fluid available for examination.

\section{Clinical Features}

The patient, R. W., was found to have abnormal heart sounds at the age of five years during a routine examination at a school clinic. He remained under observation, first of Dr. Carey Coombs and later of Professor Bruce Perry, until the age of 14, when he left school. During this period health and growth were normal and there were no relevant subjective symptoms. The cardiac lesion caused no apparent disability except that sometimes after exercise he became cyanosed. Its nature was not firmly established for some years. A loud apical systolic murmur was present constantly and it was noted that there was also from time to time another apical murmur which was mid-diastolic or presystolic in character; because of the latter murmur the possibility of a rheumatic origin was considered. From 14'to 17 years of age he worked in a factory, where his work included vigorous physical exertion, such as the moving of heavy packing cases: he had infrequent attacks of headache and vomiting. Later he worked as an A.R.P. messenger and he rendered good service during the air raids on Bristol. At the age of 17 years, on July 10, 1941 he had a sudden fainting attack, details of which are not available. On July 15 , he had a severe attack of vomiting, lasting a few hours and followed, on the evening of the next day, by a sudden violent frontal headache attended by neck rigidity; this persisted until his admission to hospital on July 17, with a tentative diagnosis of acute meningitis. On examination in hospital the patient, a strongly built youth, had slow slurred speech and slow cerebration. Temperature and pulse and respiratory rates were normal. There was marked neck rigidity and Kernig's sign was positive on both sides, but there was no head retraction, and the abdominal and tendon reflexes were normal, and the plantar reflex on both sides was flexor. There were no signs of cranial nerve lesions, and the motor and sensory systems appeared normal. The cerebrospinal fluid was heavily blood-stained and under slightly increased pressure. 60 c.c. were withdrawn; three tubes were used to collect the fluid and in each the proportion of blood appeared to be about the same; it was free from clot. There was no relative increase in leucocytes; the protein was $20 \mathrm{mg}$.; chlorides, $760 \mathrm{mg}$.; and urea, $43 \mathrm{mg}$.; each per 100 c.c. On centrifugalization the supernatant fluid was quite clear and colourless.

Cardiovascular system.-The apex beat was very forcible and was situated in the fifth left interspace, one inch outside the mid-clavicular line. The first heart sound was completely replaced by a loud prolonged rasping murmur heard all over the præcordium. Pulsating vessels could be seen and felt in many areas of the chest wall, particularly, on both sides of the sternum, near the anterior axillary folds, over the upper part of the rectus sheath, and at the back between the inner borders of the scapulæ. A murmur similar to the cardiac murmur could be heard over many of the dilated super- 
ficial arteries and was particularly marked just above and medial to the angle of the right scapula. The radial pulses were equal, full, and bounding, and the blood pressure in both arms was 220/120. The pulse in the femoral arteries could not be felt although a slight pulsation was felt in the left dorsalis pedis artery. The systolic blood pressure in the legs could not be determined accurately, the readings varying between 120 and 130; the diastolic pressure could not be determined. The lungs appeared normal and there were no other relevant findings.

On July 18 he was much better. The headache had gone. Slight ptosis of the left eyelid was observed. The cerebrospinal fluid was blood-stained, the pressure normal, the supernatant fluid straw-coloured, protein $25 \mathrm{mg}$., urea $43 \mathrm{mg}$., sugar $71 \mathrm{mg}$., each per 100 c.c. No relative increase of leucocytes, Wassermann reaction negative, culture sterile. A small quantity of cerebrospinal fluid was withdrawn twice daily for the next few days; the fluid became progressively clearer. On July 20 the neck rigidity had disappeared, the ptosis was diminished, and the speech somewhat improved. Radiographic examination showed an enlarged left ventricle and the characteristic notching of the ribs. No enlargement of the aortic arch could be seen. Progress continued satisfactorily and when he was discharged from hospital on August 16,1941, he was mentally normal, his speech was normal, and there was no ptosis of the eyelid. At no time was there any elevation of temperature, pulse, or respiration. He seemed strikingly untroubled by his grave cardiac lesion and he presented the robust physique commonly associated with the so-called adult type of aortic coarctation. He returned to work and remained well, without headaches, for the next 13 months. He was, howeve:-, found dead in bed one morning, having died sometime during the night: he had felt perfectly well when going to bed on the previous evening.

\section{Pathological Examination}

The body was that of a well-nourished and well-developed youth. There were no external abnormalities. The serous cavities, with the exception of the pericardium, were normal, and the internal organs with the exceptions described below, appeared normal apart from a moderate acute congestion. The thymus weighed 45 grams.

Heart and Aorta. The main features were a supernumerary mitral valvular apparatus, a marked hypertrophy of the left ventricle, bicuspid aortic valves, fusiform dilatation of the ascending aortic arch with dissecting aneurysm and consequent rupture into the pericardial sac, almost complete coarctation of the so called adult type, and anomalous great vessels (Fig. 1).

The heart weighed 550 grams, mostly the result of a well-marked hypertrophy of the left

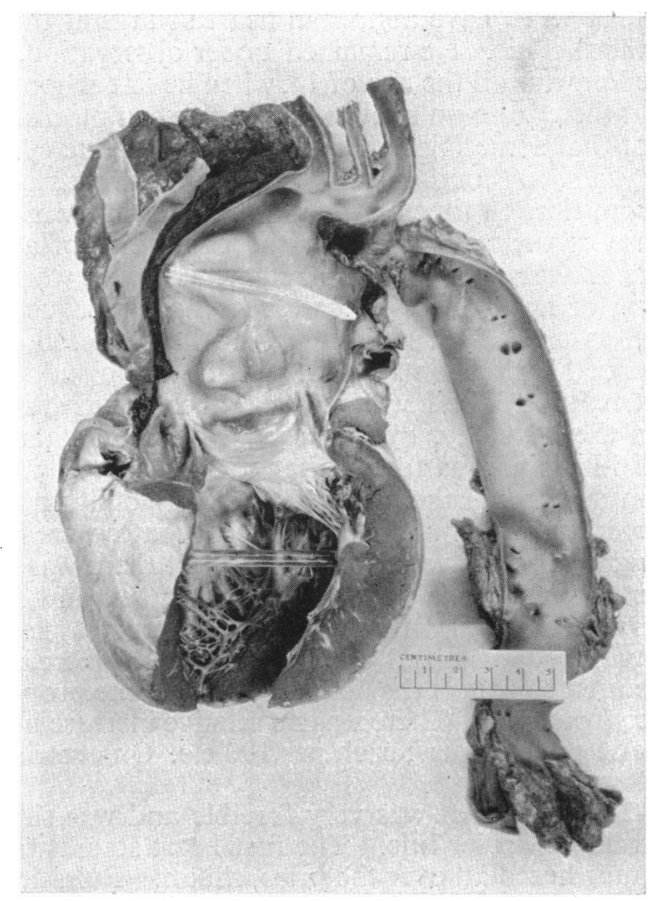

FIG. 1.-To show the coarctation, and the four vessels arising from the aortic arch. The arrow points to the rupture of the intima. 
ventricle, the wall of which was $20 \mathrm{~mm}$. thick. The left auricle appeared normal. The main mitral valve ring was $55 \mathrm{~mm}$. in circumference. In the middle of its aortic cusp there was a complete accessory or supernumerary mitral apparatus, the ring of which was $45 \mathrm{~mm}$. in circumference and furnished with two cusps which had a line of closure at right angles to that of the main mitral cusps. The accessory cusps were well supplied with chordæ tendineæ and papillary muscles; the cusps were well-developed, forming a narrow elongated cone (Fig. 2).

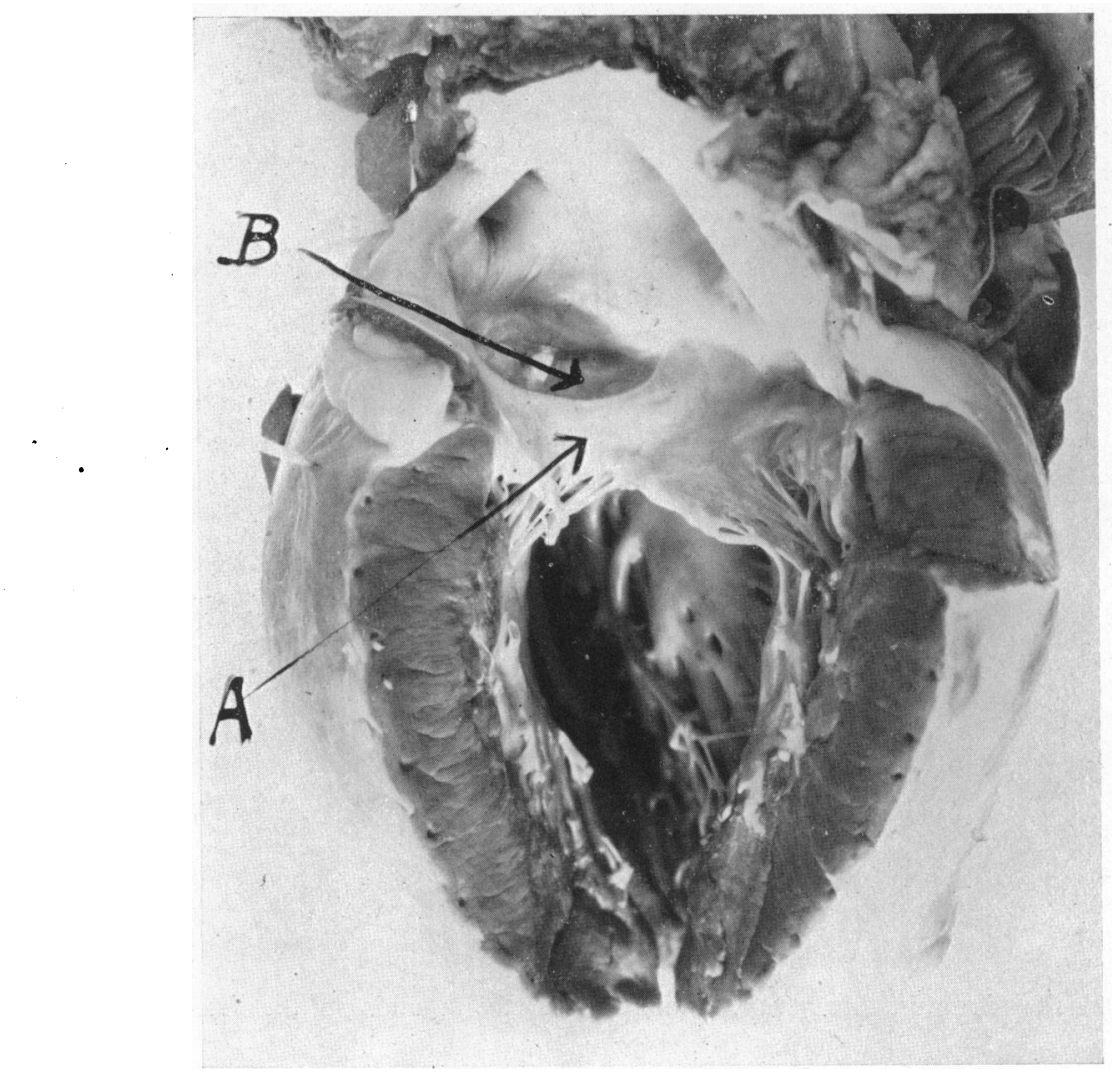

Fig. 2.-To show the double auriculo-ventricular mitral orifice, the left ventricle and the left auricle have been cut open and one cusp of the mitral valve divided and cut away. Facing is the aortic cusp of the mitral valve (marked A) with the supernumerary orifice: at the base of the opening (marked B) a small part of the left ventricular cavity can be seen.

There was no sclerosis or fenestration of any of the heart valves. The bicuspid aortic valves showed a slight diffuse thickening which rendered them more opaque than normal. The valve ring was $90 \mathrm{~mm}$. in circumference. Both coronary arteries arose from the posterior cusp and there was no raphe in either aortic sinus. There were no other notable findings in the heart. The other measurements were: right ventricle, $5 \mathrm{~mm}$. thick; circumference of the tricuspid ring, $100 \mathrm{~mm}$., and of the pulmonary ring, $70 \mathrm{~mm}$.

In the ascending aorta the fusiform dilatation showed a maximum circumference of approximately $130 \mathrm{~mm}$., the aorta narrowing at the site of origin of the great vessels to a circumference of $25 \mathrm{~mm}$. At the origin of the foetal isthmus there was a further considerable narrowing, the diameter showing a maximum of $5 \mathrm{~mm}$.; the isthmus continued as a coneshaped tube to the site of the coarctation, which admitted a hair-like probe after some manipulation. The site of the coarctation was at the attachment of the obliterated ductus. Below the coarctation the aorta rapidly widened to a circumference of $38 \mathrm{~mm}$. The great vessels arose from the arch in four main branches which could not be traced out under the circumstances of the autopsy. 
A dissecting aneurysm originated in a linear breach of the aortic intima, $35 \mathrm{~mm}$. in length, and commencing $20 \mathrm{~mm}$. above the posterior aortic cusp. The dissecting aneurysm extended, by a splitting of the media, from the root of the aorta to the origin of the great vessels to form a cuff-like sheath of blood. At a point in the aorta opposite the origin of the dissection the blood ruptured outwards into the pericardial cavity, resulting in a hæmopericardium, which was the immediate cause of death. Histologically (Fig. 3), at the site of origin of the dissection, there were numerous focal defects of elastic tissue in the media and the blood had ruptured

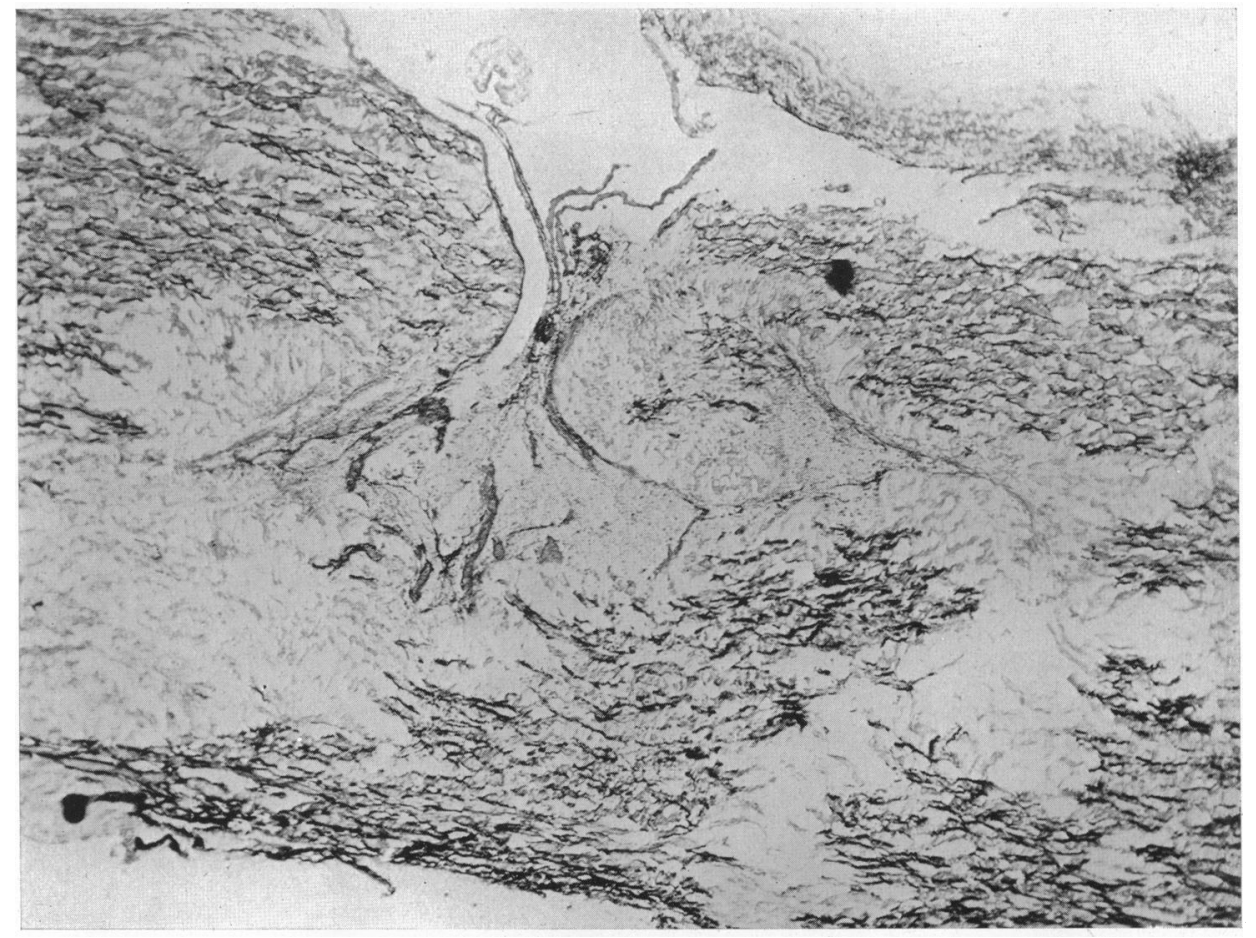

FIG. 3.-Aorta at the site of rupture through the intima, showing the beginning of the dissection. Magnification $\times 50$.

through the intima into one of these breaches in the elastica. Similar focal defects with replacement by hyaline collagenous material were observed in sections taken from the ascending aorta in other sites and in a section from the aorta below the coarctation.

Below the coarctation the intercostal arteries showed considerable enlargement; at the orifices of these arteries there were a few smooth yellow patches of atheroma in the aortic intima. There was also an occasional yellow streak of intimal atheroma, both above and below the coarctation. There was no fatty intimal change at or near the origin of the dissecting aneurysm.

In the brain there was a berry aneurysm $1 \mathrm{~cm}$. in diameter (Fig. 4), situated on the left middle cerebral artery just beyond its first main division as it passed on to the island of Reil. Above this berry aneurysm, about $4 \mathrm{~cm}$. distant, there was a cyst in the brain substance which contained a faintly brown fluid. The cyst was about $2 \mathrm{~cm}$. in diameter and the wall showed a deep yellow pigmentation. The adjacent pia-arachnord showed a similar discoloration. No aneurysm could be identified in the small artery which passed into the wall of the cyst, but it appeared most likely that this lesion resulted from a leakage from a second aneurysm rather than from the aneurysm several centimetres distant. No other abnormalities were found in the brain or the meninges. Numerous sections of the arteries forming the circle of Willis were examined microscopically. Occasional defects of the muscular coat were observed of the type commonly found in normal subjects. Sections stained by Verhoeff's elastic tissue stain 


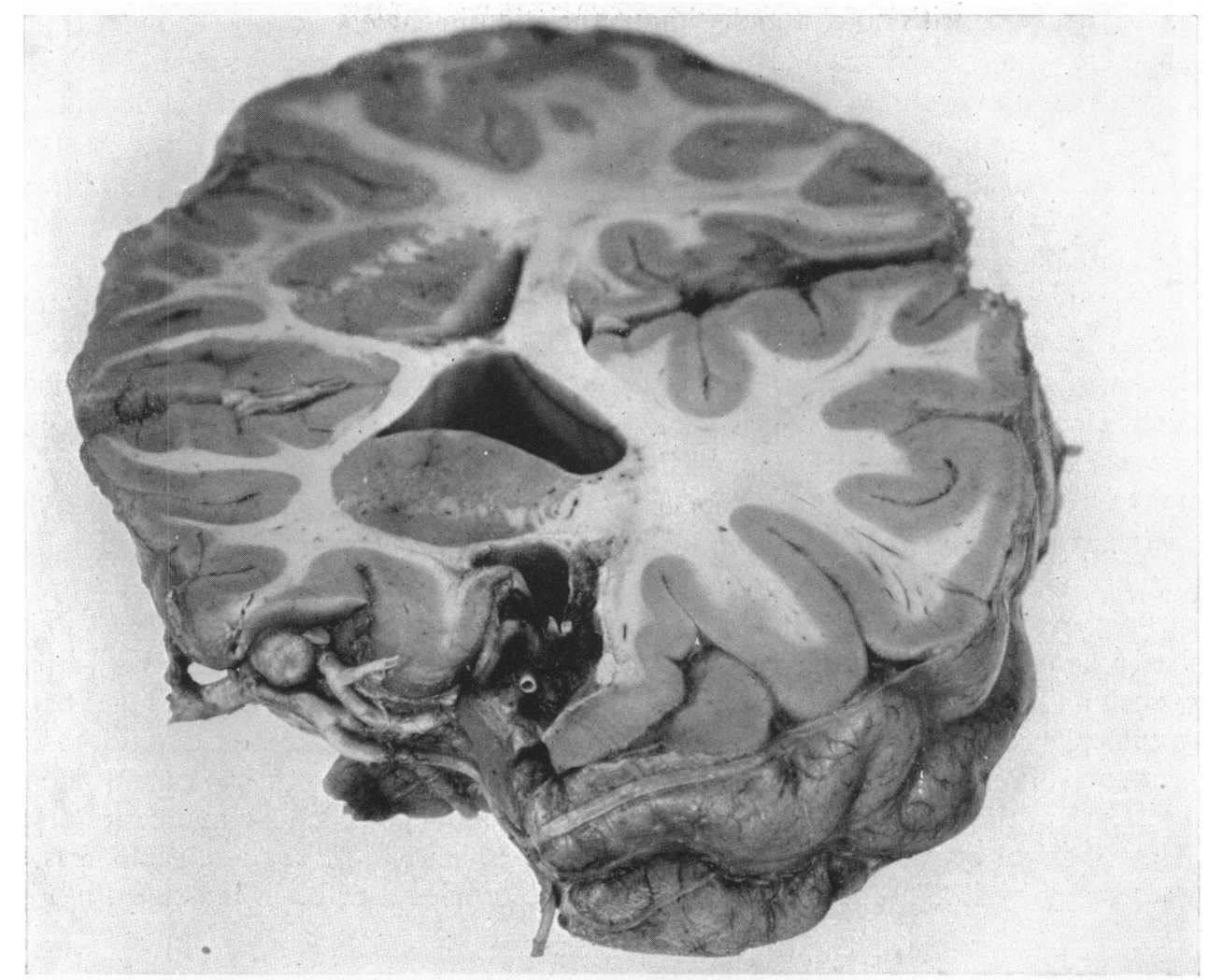

FIG. 4.-Cross-section of brain to show the aneurysm and the area of hæmorrhagic infarction.

followed by a modification of Masson's trichrome stain showed several irregularities and breaches in the internal elastic lamina reminiscent of the elastica defects in the aorta (Fig. 5). There was no atheroma of the cerebral vessels.

The left kidney weighed $200 \mathrm{~g}$.; the right, $207 \mathrm{~g}$. In both the capsule stripped easily leaving a smooth underlying surface. On section the normal architecture was clearly defined and there was moderate acute congestion. There was a normal proportion between cortex and medulla, the ratio being approximately $3: 1$. The main renal arteries appeared normal. Apart from acute congestion, no pathological change was observed. Several sections of the kidneys stained with Masson's trichrome stain were examined with the object of observing the Goormaghtigh bodies. No hypertrophy or hyperplasia of the Goormaghtigh cells was observed, and Lieut.-Colonel F. Bayless, U.S.A.M.C., kindly examined the sections and confirmed this observation. The small arteries and arterioles showed no muscular hypertrophy or other change.

\section{Discussion}

The association between intracranial aneurysm and coarctation is an interesting one. Abbott (1928) considered that an intracranial aneurysm was most probably present in all cases of coarctation terminating with an intracranial hæmorrhage before the end of the second decade, where there was no history of infection or other apparent cause. She estimated that intracranial hæmorrhage was the cause of death in about 10 per cent of cases of the so-called adult type. In view of the high cephalic blood pressure in coarctation it is not surprising that recorded clinical cases of recovery from intracranial hæmorrhage with associated aortic coarctation are so very rare. In the present case the diagnosis of subarachnoid hæmorrhage was established by the finding of blood-stained cerebrospinal fluid. This fluid was obtained twenty-four hours after the onset of violent headache and neck rigidity, which was presumably the result of blood leaking into the subarachnoid space. The fluid showed an even 
admixture of blood, with no clot and without variation in three successive samples from the first puncture, and the supernatant fluid was quite clear. Merritt and Fremont-Smith (1937) state that the cerebrospinal fluid will be yellow or xanthochromic if it has contained blood for more than four hours before removal. We consider that the evidence in this case is strongly in favour of the blood not being traumatic in origin and that it suggests that exceptions can occur to Merritt and Fremont-Smith's generally accepted statement. In the case under discussion subsequent specimens showed considerable hæmolysis.

An underlying factor common to intracranial aneurysm and aortic coarctation can now be considered in view of Glynn's (1940) observations on elastic tissue defects in intracranial arteries associated with aneurysm. Glynn directs attention to the importance of lesions of the elastic elements in the intracranial arteries in the genesis of these aneurysms, pointing out that the medial muscular defects can have little ætiological significance, occurring as they do in about 80 per cent of the population. He confirms that there is a peculiar concentration of the elastic tissue into the internal elastic lamina in the muscular cerebral arteries. From inflation experiments he shows that the unsupported internal elastic lamina can withstand a pressure twice as high as the highest recorded in cases of high blood pressure, and he suggests that the main strength of these vessels, concentrated as it is into one inner layer, is very susceptible to injury such as encroachment by atheroma; and he thinks it justifiable to conclude that this topographical peculiarity is also responsible for aneurysm formation as a result of nonatheromatous degeneration of elastic fibres. In view of Glynn's work we examined several serial sections of the circle of Willis in our case and found a considerable number of areas in which the internal elastic lamina showed a focal thinning or interruption, sometimes with replacement by hyaline fibrous tissue. An example of such a defect is illustrated in Fig. 5,

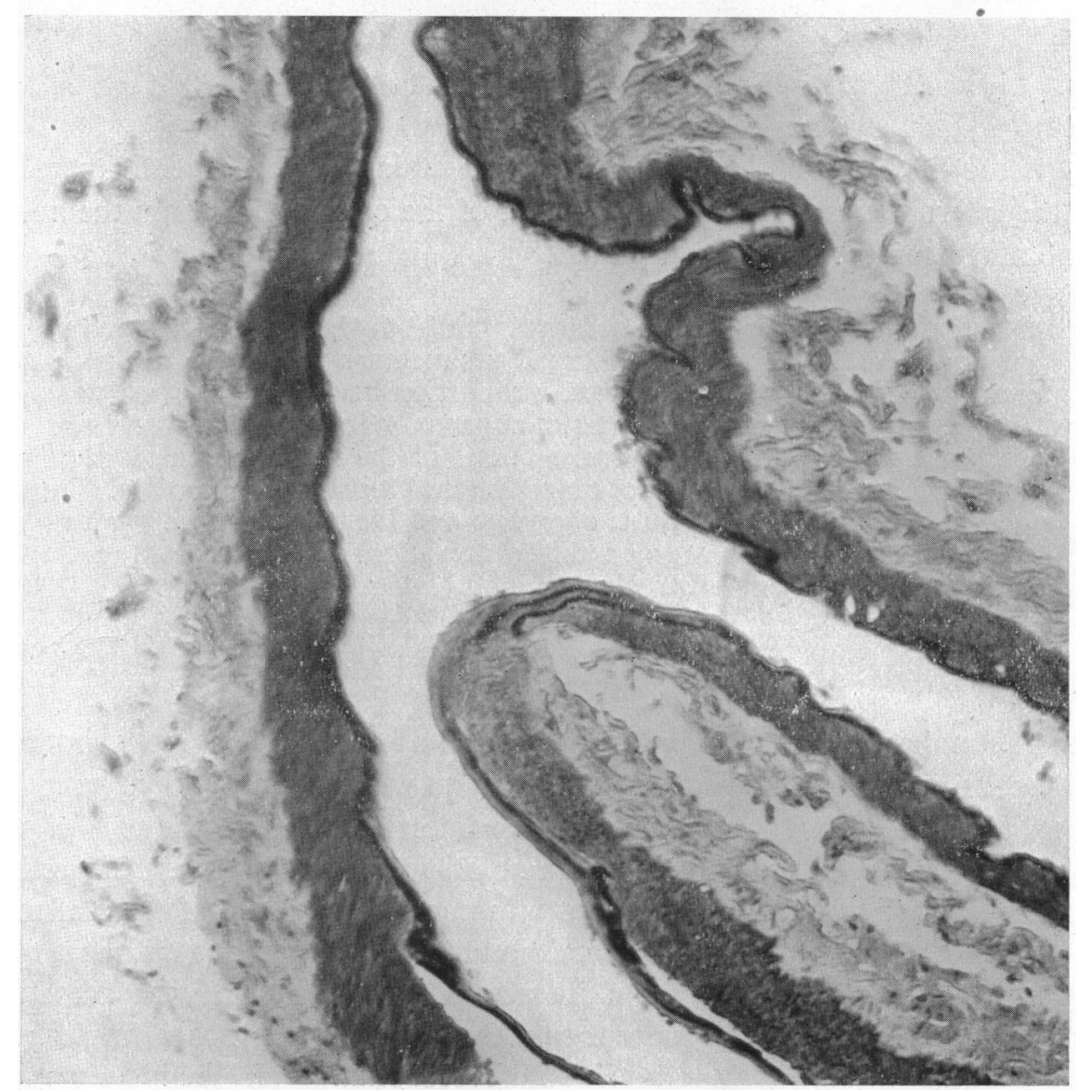

Fig. 5.-Breach of internal elastic lamina. Circle of Willis artery. S Staining, Verhøef, and Masson. Magnification $\times 155$. 
and until we have the opportunity of examining an adequate series of normal cases to serve as controls we are unable to indicate their precise significance; but they are sufficiently striking to merit further attention, and they direct attention to a single pathological process which may be common to two anomalies having a marked clinical association, notably intracranial berry aneurysm and coarctation of the aorta. We consider that the weakening of the internal elastic lamina, which we believe existed in our case, is a condition similar in ætiology to the focal hyaline defects in the elastic tissue in the aorta. These defects were found microscopically in 12 out of 13 cases of rupture of the aorta reviewed by Abbott (1928), and they were present in our case above and below the coarctation (Fig. 6). There is no reasonable doubt

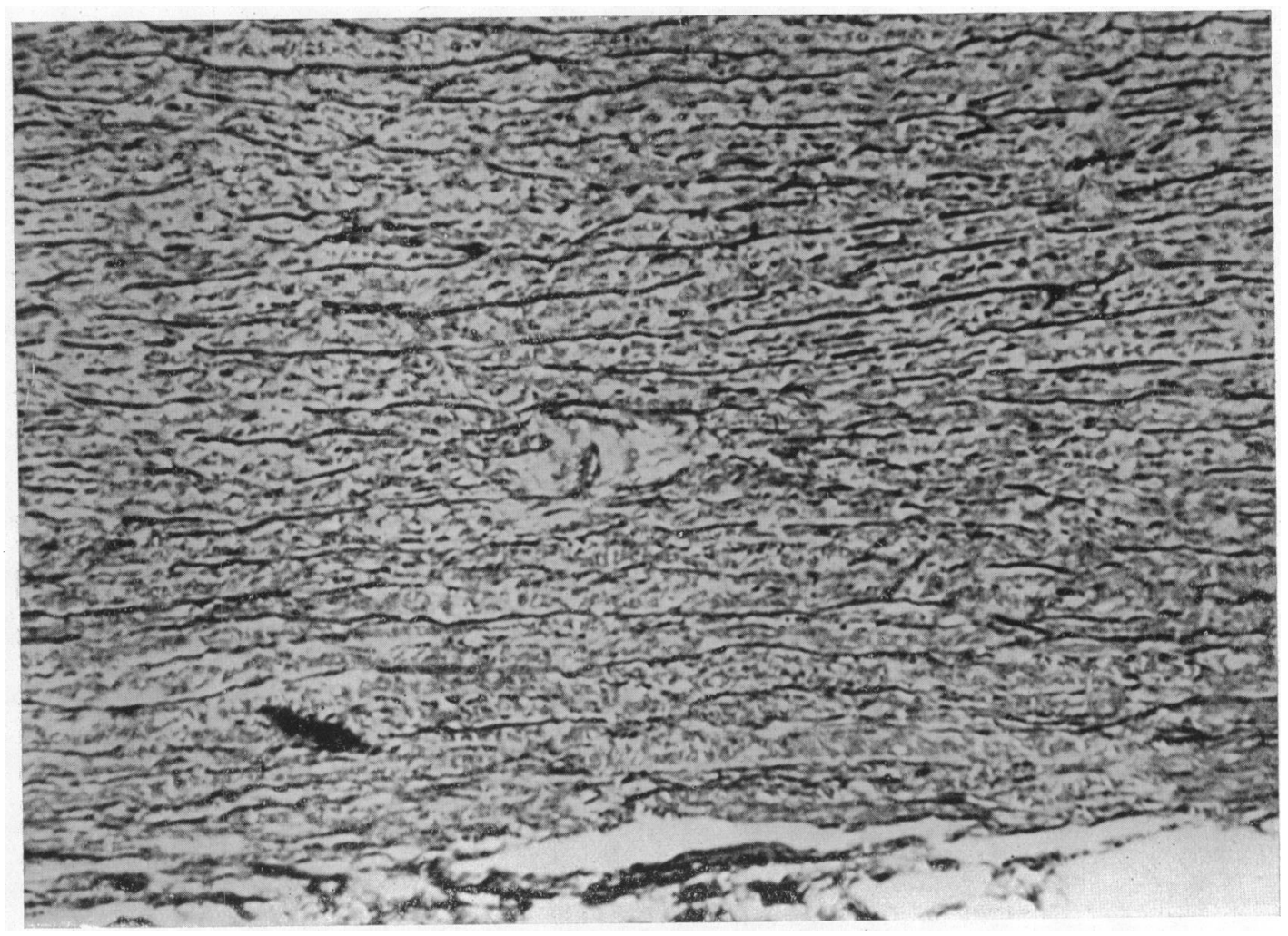

FIG. 6.-Elastica defects below the coarctation. Similar defects were shown in a micro-photograph above the coarctation, some distance from the point of rupture, but the figure has not been included. Magnification $\times 50$.

that these defects in the aorta, congenital in origin, are the ætiological factor in the great majority of cases of aneurysm and rupture of the aorta associated with coarctation. They provide a striking parallel to the weakness of the elastica in the cerebral-vessels. Shennan (1934) in reviewing 300 cases of dissecting aneurysm of the aorta decided that primary degenerative changes in the media were the most important factors and that some degree of stenosis of the aortic isthmus was not uncommon; in some of his cases there were symptoms suggesting a local lesion in the brain.

Clinically the occasional diastolic or presystolic heart murmur was possibly due to the supernumerary mitral valve. This murmur made it necessary at one period to consider the presence of rheumatic heart disease; that was, however, excluded at the autopsy. There is some obscure relationship between the aortic calibre and the presence of double mitral orifice for in two of the ten cases of double mitral orifice previously reported (Abbott, 1936) there was an associated aortic hypoplasia. The present case emphasizes this association, but we are unable to suggest any reason for its occurrence. Anatomical opinion that we have sought 
considers that the two abnormalities cannot be explained satisfactorily on a single aberrant embryological process.

\section{SUMMARY}

The case is reported of a male, aged 17, with coarctation of the aorta and other congenital defects. He developed a cerebral hæmorrhage from a berry aneurysm, and made a complete recovery from this, only to die later from rupture of the aorta.

The autopsy revealed that, in addition to the coarctation of the aorta and associated defects of elastic tissue, there was a double mitral valve. The probable counterpart during life of this rare anomaly was a presystolic or diastolic murmur in the mitral area.

The relationship of these defects is briefly discussed.

We wish to thank Professor C. Bruce Perry for his clinic notes and Mr. T. J. H. Cooke who took the photographs.

\section{REFERENCES}

Abbott, M. (1927). Osler and Macrae, Modern Medicine, Kimpton, London, 1927.

(1928). Amer. Heart J., 3, 392 . An Atlas of Congential Heart Disease, American Heart Association.

Baker, T. W., and Sheldon, W. D. (1936). Amer. J. Med. Sc., 191, 625.

Glynn, L. E. (1940). J. Path. Bact., 51, 213.

Lichtenberg, H. H., and Gallagher, H. F. (1933). Amer. J. Dis. Chil., 1, 1253.

Merritt and Fremont-Smith (1937). The Cerebrospinal Fluid, Saunders, London, 1937.

Shennan, T. (1934). Med. Research Council Special Report, Series No. 193. 